(C) 2021, The Authors. Published by Elsevier Inc. and Fass Inc. on behalf of the American Dairy Science Association ${ }^{\circledR}$. This is an open access article under the CC BY-NC-ND license (http://creativecommons.org/licenses/by-nc-nd/4.0/).

\title{
Cross-sectional analyses of a national database to determine if superior genetic merit translates to superior dairy cow performance
}

\author{
S. C. Ring, ${ }^{1 *} \odot$ R. D. Evans, ${ }^{1} \oplus$ A. R. Cromie, ${ }^{1}$ and D. P. Berry ${ }^{2} \odot$ \\ ${ }^{1}$ Irish Cattle Breeding Federation, Highfield House, Shinagh, Bandon, P72 X050, Co. Cork, Ireland \\ ${ }^{2}$ Teagasc, Animal \& Grassland Research and Innovation Centre, Moorepark, Fermoy, P61 P302, Co. Cork, Ireland
}

\begin{abstract}
Various studies have validated that genetic divergence in dairy cattle translates to phenotypic differences; nonetheless, many studies that consider the breeding goal, or associated traits, have generally been small scale, often undertaken in controlled environments, and they lack consideration for the entire suite of traits included in the breeding goal. Therefore, the objective of the present study was to fill this void, and in doing so, provide producers with confidence that the estimated breeding values (EBV) included in the breeding goal do (or otherwise) translate to desired changes in performance among commercial cattle; an additional outcome of such an approach is the identification of potential areas for improvements. Performance data on 536,923 Irish dairy cows (and their progeny) from 13,399 commercial spring-calving herds were used. Association analyses between the cow's EBV of each trait included in the Irish total merit index for dairy cows (which was derived before her own performance data accumulated) and her subsequent performance were undertaken using linear mixed models; milk production, fertility, calving, maintenance (i.e., liveweight), beef, health, and management traits were all considered in the analyses. Results confirm that excelling in EBV for individual traits, as well as on the total merit index, generally delivers superior phenotypic performance; examples of the improved performance for genetically elite animals include a greater yield and concentration of both milk fat and milk protein, despite a lower milk volume, superior reproductive performance, better survival, improved udder and hoof health, lighter cows, and fewer calving complications; all these gains were achieved with minimal to no effect on the beef merit of the dairy cow's progeny. The associated phenotypic change in each performance trait per unit change in its respective EBV was largely in line with the direc-
\end{abstract}

Received November 25, 2020.

Accepted March 14, 2021.

*Corresponding author: sring@icbf.com tion and magnitude of expectation, the exception being for calving interval. Per unit change in calving interval $\mathrm{EBV}$, the direction of phenotypic response was as anticipated but the magnitude of the response was only half of what was expected. Despite the deviation from expectation between the calving interval EBV and its associated phenotype, a superior total merit index or a superior fertility EBV was indeed associated with an improvement in all detailed fertility performance phenotypes investigated. Results substantiate that breeding is a sustainable strategy of improving phenotypic performance in commercial dairy cattle and, by extension, profit.

Key words: animal breeding, dairy cattle, milk production, reproductive performance

\section{INTRODUCTION}

Bespoke breeding goals have been developed in many countries for a variety of species and production systems (Cole and VanRaden, 2018). Validating whether or not the trait-specific measures of genetic merit contributing to breeding goals deliver the anticipated direction and extent of phenotypic change is fundamental to (a) instilling confidence within the respective sector, (b) forecasting phenotypic changes over time, and (c) identification of potential areas for further investigation and improvement. Quantifying the extent of phenotypic change per unit change in EBV is useful for breeders and producers as well as extension officers who often extrapolate EBV to derive anticipated levels of on-farm performance at the level of the cow or herd genetic merit. Such information is also useful to identify animals that deviate from expectation.

Ideally, a 1-unit change in EBV should translate to an equivalent 1-unit change in observed animal performance in the average environment; many studies in cattle have validated such hypotheses both when genetic divergence was defined at the individual trait level (Twomey et al., 2016; Judge et al., 2019; Ring et al., 2019) or at the overall breeding goal level (Connolly et al., 2016; Newton et al., 2017; Berry and Ring, 2020; 
Fessenden et al., 2020; Twomey et al., 2020a). Based on a controlled validation study of 272 Irish HolsteinFriesian cows, O'Sullivan et al. (2019) documented a regression coefficient between milk yield, fat yield, and protein yield per unit change in their respective trait PTA (i.e., half the EBV) of $1.66 \mathrm{~kg}$ (95\% CI: 1.17, $2.14), 1.47 \mathrm{~kg}(95 \% \mathrm{CI}: 0.96,1.98)$, and $1.11 \mathrm{~kg}(95 \%$ CI: $0.52,1.71)$, respectively; the expected coefficient was $2 \mathrm{~kg}$. An Australian study on 43,941 Holstein and Jersey cows also demonstrated that supplementary feeding influenced the magnitude of phenotypic differences observed between cows that diverged on genetic merit (Morton et al., 2015). Albeit from a small controlled study, O'Sullivan et al. (2020) documented superior fertility performance in genetically elite cows relative to genetically average cows when ranked on the Irish total merit index, (i.e., the Economic Breeding Index; EBI). Newton et al. (2017) quantified that high genetic merit Australian dairy cows, ranked on their Balanced Performance Index (i.e., Australian total merit index), achieved $\mathrm{A} \$ 150$ to $\$ 235$ per cow additional net profit per year than their genetically inferior herd-mates (at time of writing, 1 Australian dollar $=$ US $\$ 0.76$ ); that study (Newton et al., 2017) was based on just 3 herds. Based on analyses of 2,185 dairy cows from 5 US herds, Fessenden et al. (2020) observed favorable phenotypic differences in milk, fat, and protein yield, live calves, time spent in the lactating herd, and cow mortality between cows that diverged on their genetic merit for the Dairy Wellness Profit Index. These studies (Newton et al., 2017; O'Sullivan et al., 2019, 2020; Fessenden et al., 2020) represent much of the published research on validation of EBV comprising national dairy breeding goals, which typically consider few animals, are generally limited in both genetic lineages and farming practices, and are generally limited to the study of a few traits. Due to the paucity of such studies internationally (Pryce et al., 2018), it is necessary to validate the constituent EBV of the Irish total merit index under a commercial setting with a large relevant data set. Such analyses are required to demonstrate the robustness of traits included in national breeding goals, but also the breeding goal itself, and to substantiate whether or not results from such experimental studies (Newton et al., 2017; O'Sullivan et al., 2019, 2020; Fessenden et al., 2020) can be extrapolated to the national population.

Therefore, the objective of the present study was to quantify the association between both the Irish total merit index (i.e., the EBI) and its constituent traitspecific EBV with a suite of performance traits. This was achieved using a cross-sectional analysis of commercial dairy herd data consisting of up to 536,923 cows from 13,399 spring-calving Irish herds. The EBV used in the association analyses were those generated when the females included in the analyses were just 15 mo (i.e., typical age of first service), thus avoiding any environmental covariance between the EBV and the phenotypic data used in the validation; more importantly, the EBV used in the present study mimic the reality which would exist commercially when producers select heifers for retention. Results will be invaluable to breeders and producers alike who want to breed the "ideal" cow for a targeted production system (e.g., desired level of milk yield) as well as extension officers for educational purposes, and to the agricultural industry as a whole to provide confidence that the traits included in the EBI, as well as the EBI itself, are fit for purpose. Moreover, the methods applied in the present study can be replicated internationally to demonstrate that genetic divergence translates to phenotypic divergence, and by extension, the value of genetics to improving farm profitability.

\section{MATERIALS AND METHODS}

\section{Data}

Data from singleton dairy cows born in the Republic of Ireland between January and May, inclusive for the years 2012 to 2015, inclusive were obtained from the Irish Cattle Breeding Federation database (www.icbf .com); all 536,923 cows from 13,399 herds had both a known sire and dam with all cows calving in the herd where they were born. Only performance data arising from singleton calving events where $\geq 85 \%$ of herd-year calvings were between January and May, inclusive were available (Ring et al., 2018b); this is representative of seasonal calving production systems which predominate in Ireland (Berry et al., 2013b).

Estimated breeding values for all traits included in the Irish national breeding goal, the EBI (Berry et al., 2007; Pabiou et al., 2009; McCarthy and Veerkamp, 2012; Berry et al., 2013a,b; www.icbf.com), were available from the first national genetic evaluation in the calendar year each animal matured to 15 mo of age (i.e., eligible for breeding). The overall EBI of each cow, as well as its 7 subindexes, were constructed using the relevant PTA (i.e., half the cow's EBV) and the economic weights from the 2019 national genetic evaluation as

$$
\begin{aligned}
& \mathrm{EBI}=\text { production subindex }+ \text { fertility subindex } \\
& + \text { calving subindex }+ \text { beef subindex } \\
& + \text { maintenance subindex }+ \text { management subindex } \\
& \quad+\text { health subindex }
\end{aligned}
$$


where the subindexes are the sum of the relevant trait PTA multiplied by the respective trait economic weight (Supplemental Table S1, https://mfr.osf.io/render ?url=https: / osf.io/4mbe3/?direct $\% 26$ mode $=$ render $\% 26$ action $=$ download $\% 26$ mode $=$ render $)$.

Performance traits defined in the present study are in Table 1; they included milk yield, protein yield, fat yield, protein concentration, fat concentration, age at first calving, calved within the initial $42 \mathrm{~d}$ of the calving season, calving day of the calving season, calving to first service interval, serviced within the initial 21 $\mathrm{d}$ of the herd's breeding season, number of services, pregnant to first service, pregnant within the initial $42 \mathrm{~d}$ of the herd's breeding season, first service to conception interval, conception day, embryo loss, calving interval, survival, survival to fifth parity, calf mortality, calving difficulty, gestation length, cow liveweight, progeny carcass weight, progeny carcass conformation, progeny carcass fat, abattoir specification for progeny carcass weight, abattoir specification for progeny carcass conformation, abattoir specification for progeny carcass fat, cull cow carcass weight, arithmetic mean lactation SCS, a binary SCC trait, mastitis, lameness, milking duration adjusted for both milk yield and SCS, and finally temperament. With the exception of gestation length, calf mortality, the direct calving difficulty traits, and the progeny carcass traits, which were all defined at the level of the cow's progeny, all other traits were defined at the level of the cow herself, which was the experimental unit.

\section{Milk Production and Health Performance}

Lactation records on milk yield, protein yield, and fat yield, all adjusted to a 305-d mature equivalent, together with the arithmetic mean lactation SCC, were available for 1,157,108 lactations from 366,490 cows in 7,783 herds. The concentration of milk fat and protein per lactation were derived from the available data. Somatic cell count was normalized to SCS where SCS = $\log _{10}$ (SCC). Somatic cell count was also dichotomized as SCC200 = 1 where a cow had an arithmetic mean lactation SCS $\geq 200,000$ cells $/ \mathrm{mL}$; otherwise SCC200 was coded as 0 . Lactation records where any milk trait deviated $>3$ standard deviation units from the parity mean were omitted.

Test-day milking duration data were obtained using Tru-Test electronic milk-recording meters in herds that performed "do-it yourself" milk-recording; details of the methodology for calculating milking duration are explained by Berry et al. (2013a). Only milking duration data on 430,351 cow-lactations from 154,267 cows in 3,109 herds captured during the first $305 \mathrm{~d}$ of lactation were used.
Milking temperament in Ireland is subjectively scored per lactation by producers on a 5 -point scale $(1=$ very poor; $2=$ poor; $3=$ average; $4=$ good; $5=$ very good). Milking temperament scores were available for 17,543 lactations from 15,326 cows in 707 herds; only scores from herd-years that recorded variation in milking temperament were used. In addition, lameness and mastitis events, also recorded by producers on a per lactation basis, were available. A cow observed as lame was coded as 1 , otherwise a cow was coded as 0 ; mastitis events were coded in a similar manner. Only lameness and mastitis records from herd-years that had a respective trait prevalence of between $5 \%$ and $25 \%$ were considered (Ring et al., 2018a). A total of 118,713 lameness records from 84,440 cows in 1,800 herds as well as 213,671 mastitis records from 126,703 cows in 2,572 herds were available.

\section{Fertility Performance}

Calving events $(\mathrm{n}=3,987,978)$, pregnancy diagnoses $(\mathrm{n}=1,154,495)$, together with natural service and artificial insemination data $(\mathrm{n}=3,546,587)$, were available for $1,017,941$ cows to define the fertility performance traits. Fertility performance traits, defined per cow parity, were adapted from Berry et al. (2013b), Ring et al. (2018b), and Stachowicz et al. (2018). Breeding seasons and calving seasons were defined for each herd separately and for primiparous and multiparous cows combined. A breeding season commenced when 5 cows were serviced within $14 \mathrm{~d}$ of an initial service (Berry et al., 2013b); that breeding season terminated $140 \mathrm{~d}$ later. A calving season commenced when 5 cows calved within $14 \mathrm{~d}$ of an initial calving event (Berry et al., 2013b); that calving season terminated $140 \mathrm{~d}$ later.

Age at first calving was calculated as the difference (in days) between an animal's birthdate and date of first calving; only cows that calved for the first time between 540 and $1,240 \mathrm{~d}$ were considered. A cow that calved either up to $60 \mathrm{~d}$ before the start of a calving season, or within the initial $42 \mathrm{~d}$ of a herd's calving season, was coded as CALV42 $=1$, whereas a cow that calved $>42 \mathrm{~d}$ after a herd's calving season commenced was coded as CALV42 $=0$; cows that calved after the calving season terminated were not considered for CALV42. For cows that calved between the start and end of a calving season, calving day was defined as the number of days between the start of the calving season and the date the cow calved (Stachowicz et al., 2018).

Calving to first service interval was calculated as the number of days between a cow's calving and her first service; only calving to first service intervals between 10 and $250 \mathrm{~d}$, inclusive, were retained. Submission rate in the initial $21 \mathrm{~d}$ of a herd's breeding season was de- 
Table 1. Number or records, number of animals, number of contemporary groups (CG), as well as the mean and SD for each trait in the analyzed data set

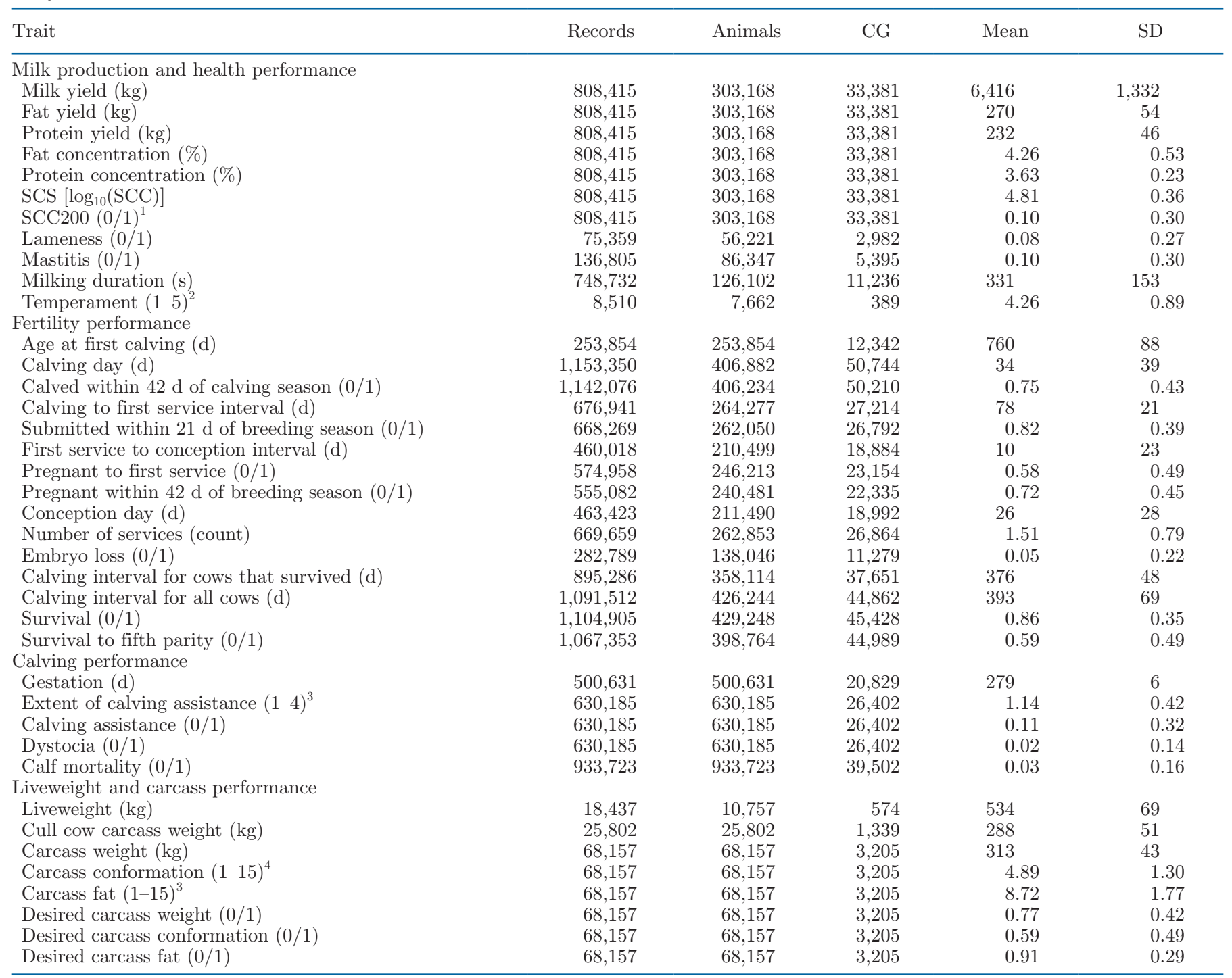

${ }^{1} \mathrm{SCC} 200=1$ where a cow had an arithmetic mean lactation SCS $\geq 200,000$ cells/mL; otherwise SCC200 was coded as 0.

${ }^{2}$ Scale of 1 (very poor temperament) to 5 (very good temperament).

${ }^{3}$ Scale of 1 (no assistance provided) to 4 (assistance provided with considerable calving difficulty resulting in veterinary intervention).

${ }^{4}$ Scale of 1 (poor carcass shape and development, little fat cover) to 15 (excellent carcass shape and development, heavy fat cover).

fined as whether a cow was serviced for the first time $(\mathrm{SR} 21=1)$ or not serviced for the first time $(\mathrm{SR} 21=0)$ during the initial $21 \mathrm{~d}$ of a herd's breeding season, irrespective of her calving date; a cow serviced for the first time either before or after a breeding season was not considered for SR21. Number of services was defined as the total number of recorded services per cow parity; number of services was set to 10 where more than 10 services were recorded.

Conception was assumed to have occurred on the date of a cow's final service event where the number of days between that final service and the cow's subsequent calving was between 260 and 300 d, inclusive. Where a subsequent calving date was not available, a cow was assumed to have conceived on her final service date provided a viable pregnancy was recorded thereafter.

First service to conception interval was defined as the number of days between a cow's first service and the assumed date of conception; first service to conception intervals up to $350 \mathrm{~d}$ were retained. A cow deemed to have conceived on the day she was first serviced was assumed pregnant to first service; a cow was assumed not pregnant to first service where the total number of services the cow received per parity was $>1$, or where 
the cow was scanned without a viable pregnancy after her first service, or where the cow calved $>313 \mathrm{~d}$ after her first service. Conception day was defined as the number of days between the start of the breeding season and the date of conception (Stachowicz et al., 2018). Irrespective of calving date, a cow was assumed pregnant if she conceived in the initial $42 \mathrm{~d}$ of a predefined breeding season (PR42=1); a cow serviced in the initial $42 \mathrm{~d}$ of a breeding season that did not subsequently calve within $313 \mathrm{~d}$ of that service together with any cow scanned without a viable pregnancy $>42$ $\mathrm{d}$ after the start of a breeding season was assumed not pregnant within $42 \mathrm{~d}$ of the breeding season (PR42 = $0)$. In addition, where no conception date was available, and a service event was recorded $>42 \mathrm{~d}$ after the start of a breeding season, that cow was assumed not pregnant within $42 \mathrm{~d}$ of the breeding season $(\mathrm{PR} 42=$ $0)$. Only cows serviced between the start and end of a breeding season were considered for PR42.

Embryo loss was only defined for cows confirmed to be pregnant (via ultrasonography, blood test, or other method) within 21 to $260 \mathrm{~d}$ after a recorded service. Where the difference between the final service date before scanning and the subsequent calving date was 260 to $300 \mathrm{~d}$, inclusive, embryo loss was assumed not to have occurred; otherwise, if a cow calved $>313 \mathrm{~d}$ after her final service event then embryo loss was assumed to have occurred. If the cow did not subsequently calve again after the confirmed pregnancy diagnosis but she remained in the herd for $>313 \mathrm{~d}$, then embryo loss was also assumed to have occurred.

Cow survival was defined at the level of the individual parity for parities 1 through 5 , inclusive, but also as a binary trait that considered whether or not the cow calved at least 5 times. A cow was assumed to have survived parity $i$ where a subsequent calving event for parity $i+1$ was registered (SURV $=1$ ); otherwise, a cow was deemed not to have survived parity $i$ (SURV $=0$ ) if she either died, was slaughtered, or $800 \mathrm{~d}$ lapsed from her most recent calving event to the date of data extraction. A cow registered with $\geq 5$ calving events was coded as 1 for the binary trait of survival to fifth parity; otherwise, a cow was coded as 0 for survival to fifth parity if she had either died or was slaughtered before her fifth calving event, or $800 \mathrm{~d}$ had lapsed since her fourth and final calving event to the date of data extraction.

Calving interval was defined in 2 ways. The first calving interval trait, which is the traditional measure of calving interval used in the EBI (Berry et al., 2013b), was defined as the number of days between consecutive calving events; only calving intervals ranging from 300 to $800 \mathrm{~d}$ were considered and only cows that survived the lactation (i.e., SURV = 1) were included. In a subsequent definition of calving interval, referred to as penalized calving interval, cows that did not survive the lactation (i.e., SURV $=0$ ) were also considered; for this trait, the calving interval for cows coded as SURV $=0$ was defined as the number of days between the cows' most recent calving date and their anticipated calving date. The anticipated calving date was defined as $21 \mathrm{~d}$ after the last recorded calving event in that herd for a given year. Otherwise, calving interval for cows coded as SURV $=1$ was defined as the number of days between consecutive calving events.

To exclude herds that typically record only a cow's final service, only the fertility performance traits of age at first calving, calving day, CALV42, embryo loss, calving interval, and survival were considered where herd-years documented only a single service event for $>80 \%$ of cows (Ring et al., 2018b).

\section{Calving Performance}

Gestation length was defined as the number of days between the last available service date for a given female and her subsequent calving date, provided the registered sire of the calf at birth concurred with the recorded sire at service. A total of 802,206 gestation length records ranging from 260 to $300 \mathrm{~d}$ in length were considered in the present study. The extent of calving assistance provided to an animal at its birth $(1=$ no assistance, $2=$ assistance provided with some calving difficulty, 3 = assistance provided with considerable calving difficulty but without veterinary intervention, $4=$ assistance provided with considerable calving difficulty resulting in veterinary intervention) was available for $1,015,934$ calves in herd-years that recorded variation. For the present study, the extent of calving assistance was dichotomized. The first binary trait, referred to as calving assistance, was coded as 0 where no recorded assistance was provided, otherwise as 1 . The second binary trait, referred to as dystocia, was coded as 0 where either no assistance or some assistance was provided, otherwise as 1 . Births coded as abortions were not considered for either gestation length or calving difficulty traits. Calf mortality was coded as 1 where the animal died within the first $5 \mathrm{~d}$ of life, or otherwise as $0 ; 1,551,024$ calf birth records were used to defined calf mortality phenotypes.

\section{Liveweight and Carcass Performance}

Liveweight records were available for 22,267 lactations from 13,240 cows in 664 herds; only one liveweight per lactation, the weight closest to mid-lactation (i.e., 
$5 \mathrm{mo}$ ), was considered. Only liveweight records taken within $300 \mathrm{~d}$ of calving in the herd of calving were considered as were liveweights within 3 standard deviation units from the parity mean.

Carcass weight, carcass conformation, and carcass fat records were available to the present study. Carcass weight was quantified postslaughter following removal of the head, legs, thoracic organs, abdominal organs, as well as the internal fats and hide (Connolly et al., 2016). Carcass conformation and carcass fat were objectively measured using Video Image Analysis (www .eplusv.de) and classified according to the standardized beef carcass grading system within the European Union (Pabiou et al., 2011). In accordance with that grading system, carcass conformation was scored on a 15 -point scale, where the number 1 denotes the poorest carcass shape and development, whereas the number 15 denotes the best carcass shape and development; carcass fat is scored in a similar fashion, on a 15-point scale, in order of increasing fatness (Englishby et al., 2016). When the supply of beef relative to demand is high, Irish abattoirs often impose monetary penalties on carcasses that do not conform to the most desirable grades (Kenny et al., 2020); as a result, binary traits indicative of whether (i.e., coded as 1 ) or not (i.e., coded as 0$)$ a carcass concurs with the desired abattoir grade for carcass weight, carcass conformation, and carcass fat were defined for the present study as per Kenny et al. (2020). The desirable carcass weight, carcass conformation, and carcass fat was 270 to $380 \mathrm{~kg}$, $\geq 5$, and between 6 and 11, respectively (Kenny et al., 2020).

Only carcass records from animals that resided in the herd from which they were slaughtered for $>100 \mathrm{~d}$ were retained. Carcass weights from cows $>3$ standard deviations from the parity mean were excluded, as were progeny carcass records from young bulls, progeny with a carcass weight more than $450 \mathrm{~kg}$, and progeny slaughtered younger than $330 \mathrm{~d}$ of age; a total of 163,516 cull cow carcass weight records from 14,521 herds and 259,468 progeny carcass records from 24,203 herds were available.

\section{Edits and Contemporary Groups}

Before contemporary group formation some final edits were imposed on the data set. Performance traits following calvings that resulted in multiple births were excluded from all analyses as were traits where a calving event occurred $<545 \mathrm{~d}$ of age or $>545 \mathrm{~d}$ from the parity median. In addition, progeny traits were only considered where the sire's EBV (from the last evaluation in the calendar year of 2019) for the respective trait were available.
Contemporary groups were defined for each trait separately, as per the Irish national dairy cow genetic evaluation, using an algorithm described in detail by Berry et al. (2013b), who adopted the methods suggested by Schmitz et al. (1991) and Crump et al. (1997). Contemporary groups were formed within herd, by amalgamating animals together that were likely to have been homogeneously managed, identified through a specific event (i.e., birth, calving, or interlocation movement event). By way of example, for the milk traits, cows that calved within $10 \mathrm{~d}$ of each other in the same herd (i.e., herd of calving) were initially clustered together; where fewer than 10 cows were initially clustered together, the group was amalgamated with an adjacent group. This process was reiterated until the contemporary group contained a minimum of 10 cows, provided the interval between the first and final calving event in the contemporary group did not exceed 100 d. For the carcass traits, the finishing herd and date of interlocation movement to the finishing herd was used for contemporary group formation. For age at first calving, CALV42, and calving day in primiparae, the herd the female resided in 9 mo before calving as well as birthdate was used for contemporary group formation; a primiparous female that moved herd between 9 and 15 mo before calving was not considered for age at first calving, CALV42, or calving day. For all other traits, contemporary groups were based on the date and herd of calving. Contemporary groups with $<15$ records were not considered in the final analysis.

Each cow was stratified into 1 of 5 categories (i.e., very poor, poor, average, good, very good) based on EBI and separately based on EBV; stratification categories were defined within contemporary group of the herd-year of first calving to avoid potential confounding between herd and genetic merit.

\section{Association Analysis}

The association between animal EBV and its respective phenotypic value was estimated using the DMU package (Madsen and Jensen, 2008). Preliminary analysis revealed regression estimates were similar (following conversion to the predicted probability scale) for the binary traits when both linear and threshold models were used; therefore, only linear mixed models were pursued in the final analysis of all traits due to the ease of interpretation of the linear model solutions relative to the threshold model results. Cow traits were evaluated according to 6 different linear mixed models while calf traits were evaluated using 3 different models depending on the trait in question. The models were as follows: 
$c o w 1=e b v+h e t+r e c+p a r i t y \times a g e+c o w+C G_{\text {calving }}+e$,

$$
\begin{aligned}
& \text { cow } 2=e b v+\text { het }+ \text { rec }+ \text { parity } \times \text { age }+ \text { stage }+ \text { session } \\
& + \text { herd } \times \text { date }+ \text { yield }+S C S+\text { cow }+e
\end{aligned}
$$$$
c o w 3=\text { fertility } e b v+\text { het }+r e c+C G_{\text {birth }}+e,
$$$$
\text { cow } 4=\text { fertility } e b v+\text { het }+ \text { rec }+ \text { parity } \times \text { age }+ \text { cow }
$$$$
+C G_{\text {calving }}+e
$$$$
c o w 5=e b v+h e t+r e c+\text { parity } \times \text { age }+ \text { stage }+ \text { cow }
$$$$
+C G_{\text {calving }}+e
$$$$
\text { cow } 6=e b v+\text { het }+ \text { rec }+ \text { parity } \times \text { age }+ \text { stage }
$$$$
+C G_{\text {movement }}+e
$$$$
\text { calf } 1=e b v+\text { sireebv }+ \text { sex }+ \text { het }+ \text { rec }+ \text { calf het }+ \text { calf rec }
$$$$
+ \text { parity } \times \text { age }+ \text { cow }+C G_{\text {calving }}+e,
$$$$
\text { calf } 2=e b v+\text { maternalebv }+ \text { sireebv }+ \text { sex }+ \text { het }+ \text { rec }
$$$$
+ \text { calf het }+ \text { calf rec }+ \text { parity } \times \text { age }+ \text { cow }+C G_{\text {calving }}+e,
$$

$$
\begin{aligned}
& \text { calf } 3=e b v+\text { service sire ebv }+ \text { het }+ \text { rec }+ \text { calf het } \\
& \quad+\text { calf rec }+ \text { parity } \times \text { age }+ \text { sex } \times \text { age }+ \text { cow }+C G_{\text {movement }} \\
& \quad+e
\end{aligned}
$$

where $\operatorname{cow} 1=$ milk yield, fat yield, protein yield, fat concentration, protein concentration, SCS, SCC200, lameness, mastitis, and temperament; cow $2=$ milking duration; cow3 = age at first calving, CALV42 in primiparae, and calving day in primiparae; cow $4=$ each of the detailed fertility traits, except age at first calving, CALV42 in primiparae and calving day in primiparae; $\operatorname{cow} 5=$ cow liveweight; cow $6=$ cull cow carcass weight; calf $1=$ gestation length and calf mortality; calf $2=$ the extent of calving assistance traits; calf $3=$ the continuous and binary traits progeny carcass traits; $e b v=$ fixed effect of the cow's EBV (defined as continuous or categorical) for the trait represented by the dependent variable; fertility ebv = fixed effect of the cow's EBV for either calving interval or survival; service sire ebv = fixed effect of the sire's EBV for the trait represented by the dependent variable; maternal ebv = fixed effect of the cow's maternal EBV for the trait represented by the dependent variable; het $=$ fixed effect of the cow's heterosis coefficient; rec $=$ fixed effect of the cow's recombination loss coefficient; calf het $=$ fixed effect of the heterosis coefficient of the calf; calf rec $=$ fixed effect of the recombination loss coefficient of the calf; parity $\times$ age $=$ fixed effect of the interaction between cow parity $(1,2,3,4+)$ and age at calving (in months) relative to the parity median; yield $=$ fixed effect of milk yield; $S C S=$ fixed effect of somatic cell score; stage $=$ the fixed effect of the number of months since the cow calved; session $=$ the fixed effect of whether the milking duration data were obtained from morning or evening milking; herd $\times$ date $=$ the random effect of the interaction between the herd and date when the milking duration data were recorded; sex $=$ the fixed effect of calf sex; sex $\times$ age $=$ fixed effect of the interaction between calf sex and age at slaughter (in months); cow $=$ random effect of the cow, where Cow $\sim N\left(0, \mathbf{I} \sigma_{\text {Cow }}^{2}\right)$ with $\sigma_{C o w}^{2}$ representing the cow variance and $\mathbf{I}$ the identity matrix; $C G_{\text {calving }}=$ the random effect of contemporary group when the contemporary group was defined based on the date and herd of calving, where $C G \sim N\left(0, \mathbf{I} \sigma_{C G}^{2}\right)$, with $\sigma_{C G}^{2}$ representing the contemporary group variance; $C G_{\text {birth }}=$ the random effect of contemporary group when the contemporary group was defined based on the herd the female resided in 9 mo before calving as well as birthdate, where $C G \sim$ $N\left(0, \mathbf{I} \sigma_{C G}^{2}\right)$ with $\sigma_{C G}^{2}$ representing the contemporary group variance; $C G_{\text {movement }}=$ the random effect of contemporary group when the contemporary group was defined based on the finishing herd and date of interlocation movement to the finishing herd, where $C G \sim$ $N\left(0, \mathbf{I} \sigma_{C G}^{2}\right)$ with $\sigma_{C G}^{2}$ representing the contemporary group variance; and $e$ is the random residual factor, where $e \sim N\left(0, \mathbf{I} \sigma_{e}^{2}\right)$ with $\sigma_{e}^{2}$ representing the residual variance.

In separate series of analyses, the models described above were modified where the fixed effect of the cow's EBV was replaced by the cow's EBI [defined as either a continuous or a categorical trait (i.e., very poor, poor, average, good, very good)] or the individual EBI subindex corresponding to the dependent variable (i.e., production, fertility, calving, beef, maintenance, management, or health). Preliminary analyses revealed a weak regression coefficient between the calving interval EBV and its associated phenotypic performance; as a result, post hoc analyses tested the interaction between the cow's calving interval EBV and her EBV strata for the same trait. The model used was the same as that described previously except the fixed effect of the cow's calving interval EBV was replaced by the fixed effect of the interaction between the cow's calving interval EBV and the cow's EBV strata for calving interval. Least 
squares means were extracted from the analysis based on a referent animal, which differed by trait.

\section{RESULTS}

\section{Descriptive Statistics and Fixed Effects}

Summary statistics including the number of records and relevant phenotypic means in the analyzed data set are in Table 1. Holstein (68\%) and Friesian (23\%) represented the main breed for most cows in the edited data set; the next most prominent breed, Jersey, was the main breed for $3.6 \%$ of cows. The mean EBI (SD in parentheses) for cows in the analyzed data set was $€ 147$ (€56; Supplemental Figure S1, https://mfr.osf.io/ render?url=https://osf.io/bgqrv/?direct $\% 26$ mode= render $\% 26$ action $=$ download $\% 26$ mode $=$ render ; in contrast, €129 (€59) was the mean EBI (SD in parentheses) for all dairy cows born in Ireland with known parentage between the years 2012 and 2015 (Supplemental Figure $\mathrm{S} 1)$. When cows in the analyzed data set were stratified on EBI, the mean EBI (SD in parentheses) of cows in the very poor EBI stratum was $€ 106$ ( $€ 51$ ), the poor EBI stratum was $€ 128$ ( $€ 51$ ), the average EBI stratum was $€ 145$ ( $€ 50$ ), the good EBI stratum was $€ 162$ (€48), and the very good EBI stratum was $€ 176$ (€53). The model solutions for parity for each performance trait considered are in Supplemental Table S2 (https: //mfr.osf.io/render?url=https://osf.io/d2wvx/?direct $\% 26$ mode $=$ render $\% 26$ action $=$ download $\% 26 \operatorname{mode}=$ render).

\section{Milk Production and Health Performance}

The associated phenotypic change in milk yield and milk solids per unit change in its respective EBV were close to the expectation of 1 , ranging from 0.89 to 1.03 units $(P<0.001$; Table 2$)$. Every 1-unit increase in milking duration EBV was associated with a 0.64$\mathrm{s}$ longer milking duration, while a 1-unit increase in temperament EBV was associated with a 1.02-unit improvement in temperament (Table 2). Higher (i.e., worse) EBV for each health trait were also associated $(P<0.001)$ with worse phenotypic health (Table 2$)$.

When EBI was fitted as a covariate in the model, superior EBI was associated $(P<0.01)$ with lower milk yield per lactation (i.e., $29 \mathrm{~kg}$ lower milk yield per 1-unit standard deviation increase in EBI; Table 3). Nonetheless, cows allocated into more favorable EBI strata did not always produce less milk [i.e., no difference $(P>0.05)$ in milk yield compared with cows categorized as very poor, poor, average, or very good based on EBI], and they did not have a lower mean
EBV for milk yield than cows categorized in worse EBI strata (Table 4). Where a reduction in milk yield was observed, for example, between the best EBI stratum (6,915 kg; SE: 3.042) and the worst EBI stratum (6,933 kg; SE: 3.642), the phenotypic differential in milk yield $(18 \mathrm{~kg})$ was much less than the expected differential based on EBV (41 kg; Table 4). Cows with a more favorable EBI (defined as a continuous or categorical trait) always produced a higher yield and concentration of both fat and protein than cows in the poorest EBI stratum (Tables 3 and 4), with the former also having a lower SCS (Tables 3 and 5). No association $(P>0.05)$ was observed between milking duration, temperament, lameness, or mastitis with EBI when it was stratified as a class effect in the model (Tables 4 and 5). However, when fitted as a covariate in the model, higher EBI was associated $(P<0.001)$ with less lameness but not milking duration, temperament, or mastitis (Table 3).

Differences among cows in subindex for production, management, or health were associated $(P<0.001)$ with an improvement in each of the component traits for the relevant subindex, except for lameness where no association was detected with the health subindex (Table $3 ; P>0.05$ ). Of note, was that selection on the production subindex alone would result in greater volume of milk produced (rather than a reduction in volume when selection is at the level of the overall index) as well as an accelerated gain in both fat yield (1.5 times faster) and protein yield (2.3 times faster) per standard deviation unit increase in the subindex $(\mathrm{SD}=€ 26.36)$ relative to the $\mathrm{EBI}(\mathrm{SD}=€ 56.37$; Table 3 ); that said, the present study did not investigate the implications on other (non-milk) traits where selection was based on the production subindex alone.

\section{Fertility Performance}

The associated phenotypic response in survival per 1-unit change in survival EBV was $0.85(P<0.001$; Table 6). Of all the nonbinary traits analyzed, the associated phenotypic change in calving interval per unit change in its respective EBV deviated furthest from the expectation of 1 (Table 6); every 1-unit improvement (i.e., reduction) in calving interval EBV was only associated with a $0.50 \mathrm{~d}$ shorter calving interval, indicating the EBV overestimates performance. On further investigation, the association between calving interval EBV and its respective phenotype differed by parity $(P$ $<0.001$ ), in that every 1-unit change in calving interval EBV was associated with a phenotypic difference of $0.53 \mathrm{~d}(\mathrm{SE}=0.026), 0.62 \mathrm{~d}(\mathrm{SE}=0.026), 0.49 \mathrm{~d}(\mathrm{SE}=$ $0.029)$, and $0.33 \mathrm{~d}(\mathrm{SE}=0.030)$ in first, second, third, and fourth plus parity cows, respectively (Supplemental 
Table S3, https://mfr.osf.io/render?url=https://osf.io/ vzq37/?direct $\% 26$ mode $=$ render $\% 26$ action $=$ download $\% 26$ mode $=$ render $)$. An interaction between calving interval EBV and EBV strata (defined within contemporary group) was also detected $(P<0.001)$; cows in the very good stratum for calving interval EBV (mean EBV: $-14 \mathrm{~d}$ ) had greater overestimation (regression coefficient $=0.67 ; \mathrm{SE}=0.040)$ than cows in the poor stratum for calving interval EBV (mean EBV: -9 d; regression coefficient $=0.94 ; \mathrm{SE}=0.041)$, the latter not being different from expectation. Interestingly, the earlier a cow calved before the herd mating start date, the longer her mean phenotypic calving interval (Figure 1) and the larger the performance overestimation in the calving interval EBV. For example, every 1-unit change in calving interval EBV was associated with a phenotypic difference of $0.84 \mathrm{~d}(\mathrm{SE}=0.162), 0.71 \mathrm{~d}$
$(\mathrm{SE}=0.104)$, and $0.30 \mathrm{~d}(\mathrm{SE}=0.083)$ for cows calved 0 to $30 \mathrm{~d}$ before the herd started breeding, 31 to $60 \mathrm{~d}$ before the herd started breeding, and 61 to $90 \mathrm{~d}$ before the herd started breeding, respectively.

Despite the deviation from expectation between the calving interval EBV and its phenotypic calving interval, both a superior calving interval EBV (i.e., lower values) and a superior survival EBV (i.e., higher values) were associated with an improvement in all detailed fertility performance phenotypes investigated (Table 6); that is, superior genetic merit for fertility and survival was associated with a younger age at first calving, earlier calving during a herd's calving season, earlier breeding and conception during a herd's breeding season, fewer services per parity, less embryonic death, shorter calving interval, as well as improved survival (Table 6). When EBI or the fertility subindex was fitted as a co-

Table 2. Regression coefficients (SE in parentheses) for each trait per 1-unit change in the EBV of the respective trait

\begin{tabular}{|c|c|c|}
\hline Trait & $\mathrm{EBV}$ & Coefficient \\
\hline \multicolumn{3}{|l|}{ Production trait } \\
\hline Milk yield (kg) & Milk yield (kg) & $1.02(0.006)^{* * *}$ \\
\hline Fat yield (kg) & Fat yield (kg) & $0.91(0.004)^{* * *}$ \\
\hline Protein yield (kg) & Protein yield (kg) & $0.89(0.006)^{* * *}$ \\
\hline Fat concentration (\%) & Fat concentration (\%) & $1.02(0.003)^{* * *}$ \\
\hline Protein concentration (\%) & Protein concentration (\%) & $1.03(0.003)^{* * *}$ \\
\hline \multicolumn{3}{|l|}{ Health trait } \\
\hline $\operatorname{SCS}\left[\log _{10}(\mathrm{SCC})\right]$ & $\operatorname{SCS}\left[\log _{10}(\mathrm{SCC})\right]$ & $0.33(0.005)^{* * *}$ \\
\hline $\operatorname{SCC} 200(0 / 1)^{1}$ & SCS $\left[\log _{10}(\mathrm{SCC})\right]$ & $0.18(0.004)^{* * *}$ \\
\hline Lameness $(0 / 1)$ & Lameness $(0 / 1)$ & $0.22(0.054)^{* * *}$ \\
\hline Mastitis $(0 / 1)$ & Mastitis $(0 / 1)$ & $0.40(0.058)^{* * *}$ \\
\hline \multicolumn{3}{|l|}{ Management trait } \\
\hline Milking duration (s) & Milking duration (s) & $0.64(0.014)^{* * *}$ \\
\hline Temperament $(1-5)$ & Temperament $(1-5)$ & $1.02(0.129)^{* * *}$ \\
\hline \multicolumn{3}{|l|}{ Calving trait } \\
\hline Gestation $(\mathrm{d})$ & Gestation (d) & $0.45(0.004)^{* * *}$ \\
\hline \multirow{2}{*}{ Extent of calving assistance (1-4) } & Direct calving difficulty $(0 / 1)^{2}$ & $1.39(0.039)^{* * *}$ \\
\hline & Maternal calving difficulty $(0 / 1)^{2}$ & $1.18(0.032)^{* * *}$ \\
\hline \multirow{2}{*}{ Calving assistance $(0 / 1)$} & Direct calving difficulty $(0 / 1)^{2}$ & $1.07(0.029)^{* * *}$ \\
\hline & Maternal calving difficulty $(0 / 1)^{2}$ & $0.89(0.024)^{* * *}$ \\
\hline \multirow{2}{*}{ Dystocia $(0 / 1)$} & Direct calving difficulty $(0 / 1)^{2}$ & $0.28(0.013)^{* * *}$ \\
\hline & Maternal calving difficulty $(0 / 1)^{2}$ & $0.24(0.011)^{* * *}$ \\
\hline Calf mortality $(0 / 1)$ & Calf mortality $(0 / 1)$ & $0.46(0.023)^{* * *}$ \\
\hline \multicolumn{3}{|l|}{ Maintenance trait } \\
\hline Liveweight (kg) & Cow liveweight $(\mathrm{kg})$ & $1.00(0.024)^{* * *}$ \\
\hline \multicolumn{3}{|l|}{ Beef trait } \\
\hline Cull cow carcass weight $(\mathrm{kg})$ & Cull cow carcass weight $(\mathrm{kg})$ & $0.88(0.022)^{* * *}$ \\
\hline Carcass weight $(\mathrm{kg})$ & Carcass weight $(\mathrm{kg})$ & $0.46(0.016)^{* * *}$ \\
\hline Carcass conformation $(1-15)$ & Carcass conformation (1-15) & $0.36(0.009)^{* * *}$ \\
\hline Carcass fat $(1-15)$ & Carcass fat $(1-15)$ & $0.45(0.023)^{* * *}$ \\
\hline Desired carcass weight $(0 / 1)$ & Carcass weight $(\mathrm{kg})$ & $0.002(<0.001)^{* * *}$ \\
\hline Desired carcass conformation $(0 / 1)$ & Carcass conformation (1-15) & $0.11(0.004)^{* * *}$ \\
\hline Desired carcass fat $(0 / 1)$ & Carcass fat $(1-15)$ & $-0.002(0.005)$ \\
\hline
\end{tabular}

${ }^{1}$ SCC200 $=1$ where a cow had an arithmetic mean lactation SCS $\geq 200,000$ cells/mL; otherwise SCC200 was coded as 0 .

${ }^{2}$ Calving difficulty is scored on a 4-point scale for the genetic evaluation; for presentation purposes, the EBV are transformed to a proportion scale, representing the proportion of a cow's progeny expected to have dystocia (i.e., scores of 3 or 4 ).

Significance from zero: ${ }^{* * *} P<0.001$. 
Table 3. Regression coefficients (SE in parentheses) for each trait per 1-SD-unit change in the relevant subindex (SI) as well as per 1-SD-unit change in the Economic Breeding Index (EBI) ${ }^{1}$

\begin{tabular}{|c|c|c|}
\hline Trait & Subindex coefficient & EBI coefficient \\
\hline \multicolumn{3}{|l|}{ Production SI } \\
\hline Milk yield (kg) & $64.33(1.681)^{* * *}$ & $-29.02(2.0181)^{* * *}$ \\
\hline Fat yield $(\mathrm{kg})$ & $9.14(0.065)^{* * *}$ & $5.93(0.0797)^{* * *}$ \\
\hline Protein yield $(\mathrm{kg})$ & $5.80(0.053)^{* * *}$ & $2.56(0.0645)^{* * *}$ \\
\hline Fat concentration (\%) & $0.11(0.001)^{* * *}$ & $0.12(0.0011)^{* * *}$ \\
\hline Protein concentration (\%) & $0.06(<0.001)^{* * *}$ & $0.06(0.0005)^{* * *}$ \\
\hline \multicolumn{3}{|l|}{ Health SI } \\
\hline $\mathrm{SCS}\left[\log _{10}(\mathrm{SCC})\right]$ & $-0.03(0.001)^{* * *}$ & $-0.02(0.0007)^{* * *}$ \\
\hline $\operatorname{SCC} 200(0 / 1)^{2}$ & $-0.02(<0.001)^{* * *}$ & $-0.008(0.0005) * * *$ \\
\hline Lameness $(0 / 1)$ & $-0.0001(0.001)$ & $-0.007(0.0015)^{* * *}$ \\
\hline Mastitis $(0 / 1)$ & $-0.01(0.001)^{* * *}$ & $-0.004(0.0012)^{* *}$ \\
\hline \multicolumn{3}{|l|}{ Management SI } \\
\hline Milking duration (s) & $-6.61(0.184)^{* * *}$ & $0.86(0.308)^{* *}$ \\
\hline Temperament $(1-5)$ & $0.05(0.008)^{* * *}$ & $0.02(0.014)$ \\
\hline \multicolumn{3}{|l|}{ Calving SI } \\
\hline Gestation (d) & $-1.04(0.009)^{* * *}$ & $-0.76(0.012)^{* * *}$ \\
\hline Extent of calving assistance (1-4) & $-0.01(0.001)^{* * *}$ & $-0.01(0.001)^{* * *}$ \\
\hline Calving assistance $(0 / 1)$ & $-0.01(0.001)^{* * *}$ & $-0.01(0.001)^{* * *}$ \\
\hline Dystocia $(0 / 1)$ & $-0.002(0.0002)^{* * *}$ & $-0.002(0.0003)^{* * *}$ \\
\hline Calf mortality $(0 / 1)$ & $-0.0004(0.0002)^{*}$ & $0.00(<0.001)$ \\
\hline \multicolumn{3}{|l|}{ Maintenance SI } \\
\hline Liveweight (kg) & $-18.21(0.455)^{* * *}$ & $-3.14(0.760)^{* * *}$ \\
\hline Cull cow carcass weight $(\mathrm{kg})$ & $-11.21(0.278)^{* * *}$ & $-0.53(0.329)$ \\
\hline \multicolumn{3}{|l|}{ Beef SI } \\
\hline Cull cow carcass weight $(\mathrm{kg})$ & $9.831(0.272)^{* * *}$ & $-0.533(0.329)$ \\
\hline Carcass weight $(\mathrm{kg})$ & $3.596(0.142)^{* * *}$ & $0.480(0.151)^{* *}$ \\
\hline Carcass conformation (1-15) & $0.068(0.005)^{* * *}$ & $-0.034(0.005)^{* * *}$ \\
\hline Carcass fat $(1-15)$ & $-0.034(0.007)^{* * *}$ & $0.023(0.008)^{* *}$ \\
\hline Desired carcass weight $(0 / 1)$ & $0.012(0.002)^{* * *}$ & $0.001(0.002)$ \\
\hline Desired carcass conformation $(0 / 1)$ & $0.021(0.002)^{* * *}$ & $-0.012(0.002)^{* * *}$ \\
\hline Desired carcass fat $(0 / 1)$ & $0.004(0.001)^{* *}$ & $-0.003(0.002)$ \\
\hline
\end{tabular}

${ }^{1}$ Production SI SD $=€ 26.36$; calving SI SD $=€ 11.70$; beef SI SD = €7.90; maintenance SI SD = €10.47; management $\mathrm{SI} \mathrm{SD}=€ 2.23 ;$ health $\mathrm{SI} \mathrm{SD}=€ 3.00 ; \mathrm{EBI} \mathrm{SD}=€ 56.37$.

${ }^{2}$ SCC200 $=1$ where a cow had an arithmetic mean lactation SCS $\geq 200,000$ cells/mL; otherwise SCC200 was coded as 0 .

Significance from zero: ${ }^{* * *} P<0.001,{ }^{* *} P<0.01,{ }^{*} P<0.05$.

Table 4. Mean (SD in parentheses) EBV for production and management traits for each of the 5 strata of Economic Breeding Index (EBI) as well as their associated LSM estimates (SE in parentheses) $)^{1,2}$

\begin{tabular}{|c|c|c|c|c|c|}
\hline Trait & Very poor EBI & Poor EBI & Average EBI & Good EBI & Very good EBI \\
\hline \multicolumn{6}{|l|}{$\mathrm{EBV}$} \\
\hline Milk yield $(\mathrm{kg})$ & $175(266)$ & $195(260)$ & $201(256)$ & $207(250)$ & $216(246)$ \\
\hline Fat concentration (\%) & $0.16(0.21)$ & $0.21(0.22)$ & $0.24(0.22)$ & $0.28(0.22)$ & $0.32(0.22)$ \\
\hline Protein concentration (\%) & $0.14(0.11)$ & $0.16(0.11)$ & $0.18(0.10)$ & $0.20(0.10)$ & $0.22(0.10)$ \\
\hline Milking duration (s) & $0.18(14.03)$ & $-1.00(13.98)$ & $-2.03(13.67)$ & $-2.67(13.42)$ & $-4.24(12.83)$ \\
\hline \multicolumn{6}{|l|}{ LSM } \\
\hline Milk yield $(\mathrm{kg})$ & $6,933(3.642)^{\mathrm{a}}$ & $6,940(3.357)^{\mathrm{a}}$ & $6,941(3.311)^{\mathrm{a}}$ & $6,936(3.286)^{\mathrm{a}}$ & $6,915(3.042)^{\mathrm{b}}$ \\
\hline Fat yield $(\mathrm{kg})$ & $282(0.147)^{\mathrm{a}}$ & $285(0.135)^{\mathrm{b}}$ & $287(0.133)^{\mathrm{c}}$ & $289(0.132)^{\mathrm{d}}$ & $291(0.122)^{\mathrm{e}}$ \\
\hline Protein yield $(\mathrm{kg})$ & $246(0.126)^{\mathrm{a}}$ & $247(0.116)^{\mathrm{b}}$ & $248(0.114)^{\mathrm{c}}$ & $249(0.113)^{\mathrm{d}}$ & $249(0.105)^{\mathrm{e}}$ \\
\hline Fat concentration (\%) & $4.07(0.001)^{\mathrm{a}}$ & $4.10(0.001)^{\mathrm{b}}$ & $4.14(0.001)^{\mathrm{c}}$ & $4.17(0.001)^{\mathrm{d}}$ & $4.21(0.001)^{\mathrm{e}}$ \\
\hline Protein concentration (\%) & $3.54(0.001)^{\mathrm{a}}$ & $3.55(0.001)^{\mathrm{b}}$ & $3.57(0.001)^{c}$ & $3.58(0.001)^{\mathrm{d}}$ & $3.60(0.001)^{\mathrm{e}}$ \\
\hline Milking duration (s) & $247(0.435)^{\mathrm{a}}$ & $247(0.401)^{\mathrm{a}}$ & $247(0.395)^{\mathrm{a}}$ & $247(0.393)^{\mathrm{a}}$ & $247(0.365)^{\mathrm{a}}$ \\
\hline Temperament (1-5) & $4.28(0.024)^{\mathrm{a}}$ & $4.30(0.022)^{\mathrm{a}}$ & $4.30(0.020)^{\mathrm{a}}$ & $4.31(0.021)^{\mathrm{a}}$ & $4.29(0.020)^{\mathrm{a}}$ \\
\hline
\end{tabular}

${ }^{\mathrm{a}-\mathrm{e}}$ Values within rows with different superscripts differ $(P<0.001)$ from each other.

${ }^{1}$ Least squares means are adjusted to third parity cows that calved at the median age at calving with no heterosis and no recombination loss; for milking duration the referent animal was also fixed to $150 \mathrm{~d}$ postcalving (i.e., mid-lactation).

${ }^{2}$ Stratification categories were defined within contemporary group of the herd-year of the cow's first calving to avoid potential confounding between herd and genetic merit. 
variate, each 1-unit standard deviation increase in the (sub)index was associated with desirable changes in all fertility phenotypes investigated $(P<0.001$; Table 6$)$.

When EBI was fitted as a class effect in the models, cows in the very good EBI stratum had superior fertility for all traits analyzed relative to cows in the very poor EBI stratum $(P<0.001$; Table 7$)$, the exception being age at first calving where no difference was detected. Of the most notable differences, cows in the very good EBI stratum calved $3 \mathrm{~d}$ earlier, had a 3 percentage unit greater pregnancy rate during the initial $42 \mathrm{~d}$ of the herd's breeding season, had a 2 percentage unit greater survival rate, and had a 7 percentage unit higher incidence of cows that calved at least 5 times, relative to cows in the very poor EBI stratum (Table 7 ).

\section{Calving Performance}

Calving traits are an expression of the progeny of the cow; hence, a regression coefficient of 0.50 for the continuous phenotypic traits on their respective cow EBV was expected. A coefficient of $0.45 \mathrm{~d}(\mathrm{SE}=0.004)$ was obtained for gestation length (Table 2). A higher (i.e., worse) EBV for calving difficulty and calf mortality were associated $(P<0.001)$ with more difficult calvings and more calf mortality (Table 2). An interaction between EBV and parity was detected for each of the calving traits (Supplemental Table S3); the interaction suggests that the gestation length EBV overestimates the observed gestation length in primiparae more so than in multiparous cows. In addition, the interaction suggests that the calving difficulty EBV and calf mortality EBV underestimates the observed dystocia and calf mortality in primiparae, respectively, relative to multiparous cows (Supplemental Table S3). Except for calf mortality which was not associated $(P>0.05)$ with EBI when fitted as a covariate in the model, all other calving traits improved as EBI increased (i.e., shorter gestation and less dystocia; Table 3).

\section{Liveweight and Carcass Performance}

The associated phenotypic change in cow liveweight and cull cow carcass weight per unit change in its respective EBV were $1.00 \mathrm{~kg}(\mathrm{SE}=0.024)$ and $0.88 \mathrm{~kg}$ $(\mathrm{SE}=0.022)$, respectively; the expectation was 1 . For the progeny carcass traits, the associated phenotypic change in carcass traits per 1 unit change in its respective EBV was close to the expectation of 0.50, ranging from 0.36 to 0.46 units (Table 2). Also, of relevance was that as the EBV for carcass weight and carcass conformation increased, so too did the proportion of carcasses that met the desired carcass grade specifications for weight and conformation $(P<0.001$; Table 2$)$.

When EBI was fitted as a covariate in the model, higher EBI was associated with a lighter cow liveweight

Table 5. Mean (SD in parentheses) EBV for health and calving traits for each of the 5 strata of Economic Breeding Index (EBI) as well as their associated LSM estimates (SE in parentheses) ${ }^{1}$

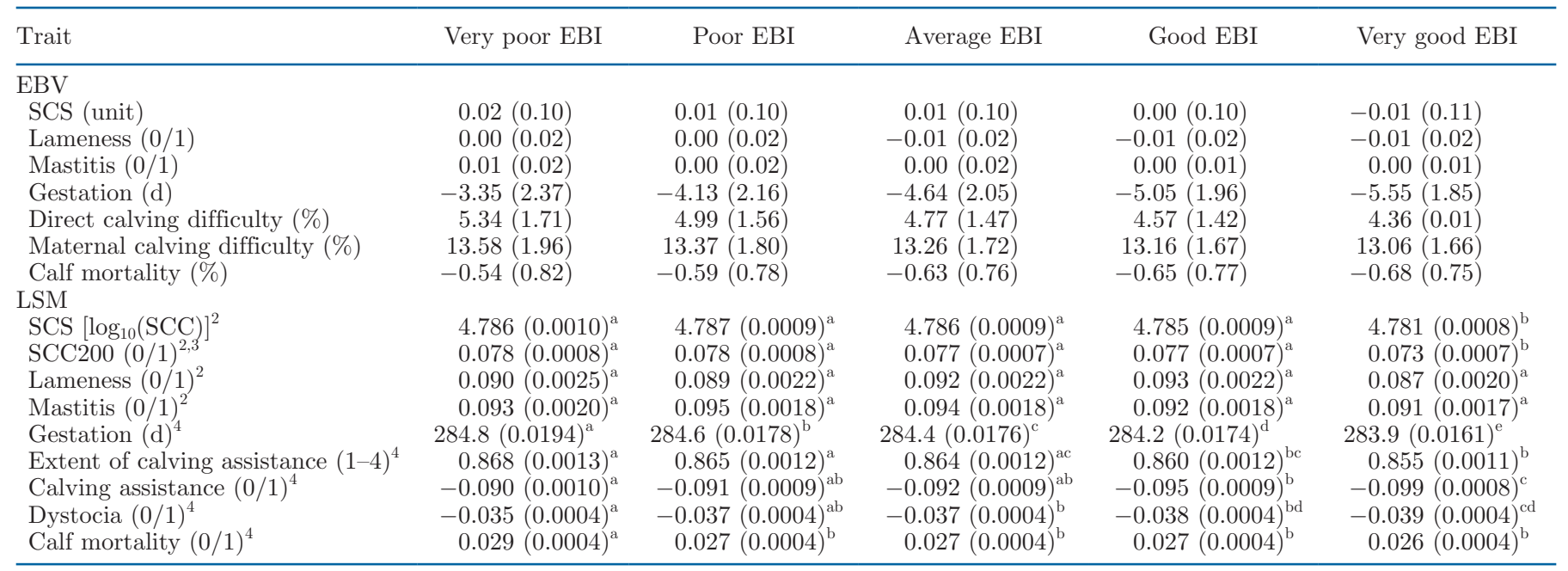

\footnotetext{
${ }^{\mathrm{a}-\mathrm{e}}$ Values within rows with different superscripts differ $(P<0.001)$ from each other.

${ }^{1}$ Stratification categories were defined within contemporary group of the herd-year of the cow's first calving to avoid potential confounding between herd and genetic merit.

${ }^{2}$ Least squares means are adjusted to third parity cows that calved at the median age at calving with no heterosis and no recombination loss. ${ }^{3} \mathrm{SCC} 200=1$ where a cow had an arithmetic mean lactation SCS $\geq 200,000$ cells/mL; otherwise SCC200 was coded as 0.

${ }^{4}$ Least squares means are adjusted to male calves with no heterosis and no recombination loss that were born to third parity dams that calved at the median age at calving with no heterosis and no recombination loss.
} 
as well as progeny carcasses that were heavier and fatter with a poorer conformation grade (Table 3); that said, all differences were biologically small. Furthermore, there was no phenotypic difference in either cow liveweight or any of the carcass traits among the 5 EBI strata (Supplemental Table S4, https://mfr.osf.io/ render?url=https://osf.io/tneam/?direct\%26mode= render $\% 26$ action $=$ download $\% 26$ mode $=$ render $)$. When selection was based on the beef subindex level, the phenotypic change in beef traits were more desirable in terms of yielding a higher carcass weight and improving carcass conformation in the progeny of the cow (Table $3)$.

\section{DISCUSSION}

Economic breeding goals provide a simple method of collapsing a series of often (antagonistically) correlated traits into a single rank to empower procedures to improve farm profitability, sustainability, or both (Ramsbottom et al., 2012; Connolly et al., 2016; Newton et al., 2017; Berry et al., 2019). Validating the suite of traits encompassing such breeding goals is fundamental to the successful adoption and extension of such tools, as well as identification of deviations from expectation that may trigger methodological improvements. Many studies have reported progressive genetic trends in cattle, both at the level of individual trait EBV (GarcíaRuiz et al., 2016; Berry, 2018; Ring et al., 2019) and at the level of the overall breeding goal (Wiggans et al., 2017; Twomey et al., 2020a); nonetheless, few studies in dairy cattle (Ramsbottom et al., 2012; Newton et al., 2017; Berry and Ring, 2020; Fessenden et al., 2020) have validated that such genetic progress translates to phenotypic improvements on-farm. The present study provides a realistic representation of the phenotypic response achievable in the average environment at a

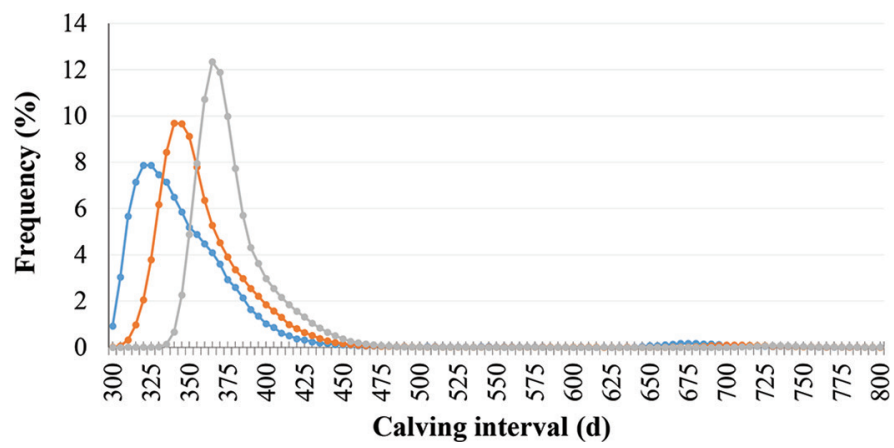

Figure 1. Distribution of calving interval for cows calved 0 to $30 \mathrm{~d}$ before the herd started breeding (blue; mean $=353 \mathrm{~d}$; SD $=60 \mathrm{~d}$ ), 31 to $60 \mathrm{~d}$ before the herd started breeding (orange; mean $=363 \mathrm{~d}$; SD $=49 \mathrm{~d}$ ), and 61 to $90 \mathrm{~d}$ before the herd started breeding (gray; mean $=380 \mathrm{~d} ; \mathrm{SD}=39 \mathrm{~d})$

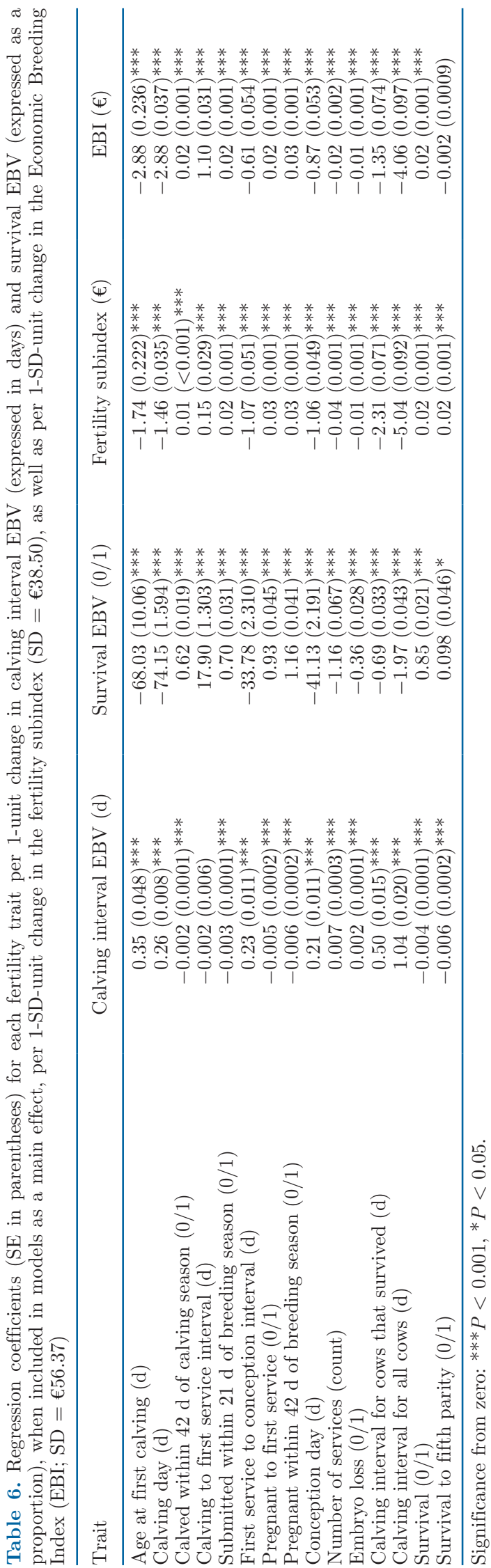




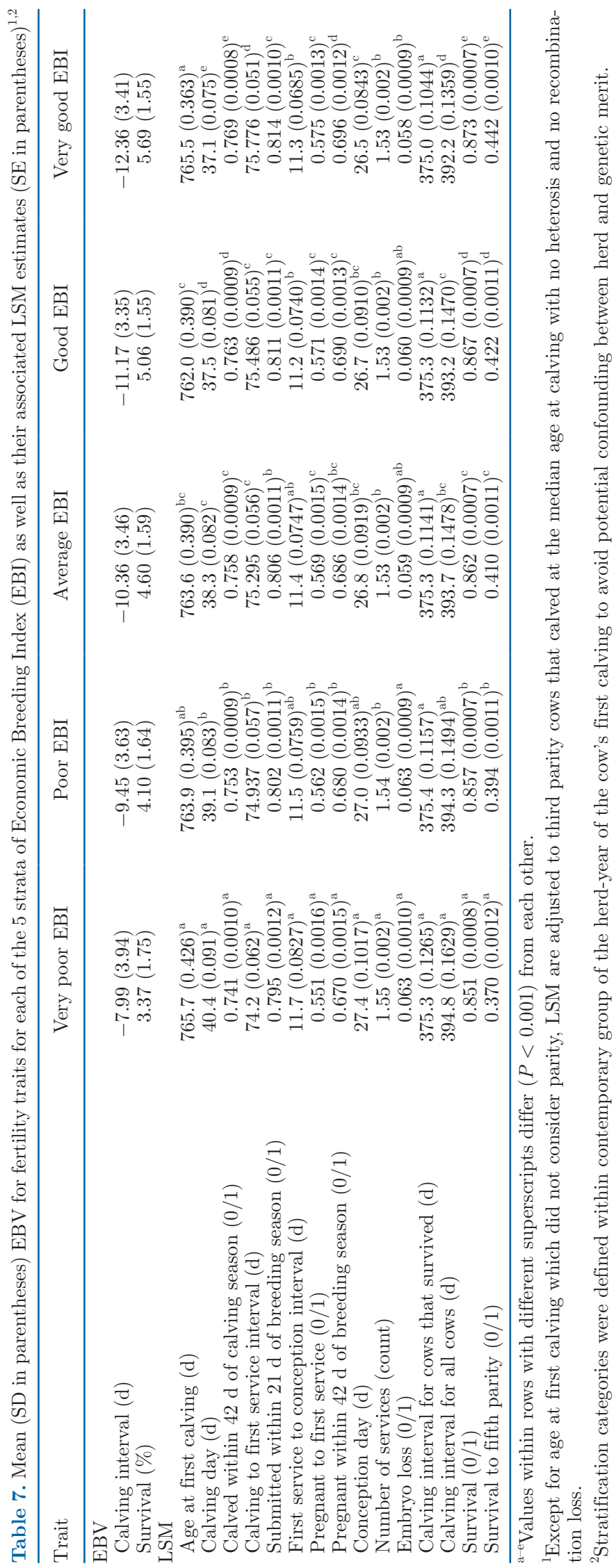

given level of genetic merit for all traits in the Irish total merit index. Results from the present study substantiate that the suite of traits that make up the Irish total merit index, and by extension the Irish total merit index itself, is generally successful in delivering superior phenotypic performance for the goal traits it aspires to change; that said, improvements can be made.

\section{The Irish Total Merit Index}

The Irish total merit index, the EBI, was launched in 2001 with the aim of identifying genetically elite dairy animals to maximize profitability in a pasture-based spring-calving production system (Veerkamp et al., 2002; Berry et al., 2007). At that time, the Irish dairy herd delivered high volumes of milk at the expense of reproductive efficiency from mostly American-Holstein ancestry (Evans et al., 2006), which were not genetically optimum for specialized grazing systems (Horan et al., 2005; Roche et al., 2017). The EBI provided a more extensive breeding objective that initially sought to improve milk production alongside reproductive performance, despite the antagonistic genetic correlation between higher milk production and compromised fertility (Olori et al., 2002; Veerkamp et al., 2002). Over time, the EBI evolved to incorporate additional economically important traits relevant to the Irish production system (Berry et al., 2007). In 2020, the EBI consisted of 18 traits compartmentalized into 7 subindexes, each with varying relative emphasis (Supplemental Table S1). With the growing number of traits included in the national breeding objective, and the accelerating rate of adoption of the breeding goal [i.e., the rate of annual genetic gain in the EBI is $€ 10.71$ or $0.19 \mathrm{SD}$ units (where the SD of the EBI is €56.37) for Irish dairy cows that first calved between the years 2010 and 2019], it is prudent that validation of the traits that encompass breeding goals in commercial herds become commonplace internationally.

The observed benefits in the present study to producers that use higher EBI animals were a greater yield and concentration of both milk fat and milk protein, despite a lower milk volume, coupled with superior reproductive performance, greater survival, superior udder health, fewer lameness events, lighter mature liveweight, and fewer calving complications; all these gains were achieved with minimal to no effect on the beef merit of the dairy cow's progeny. The findings in the present study of improved phenotypic performance in higher genetic merit animals corroborate those identified elsewhere in smaller studies. For example, a US study on 2,185 cows by Fessenden et al. (2020) reported a $32.5 \%$ increase in lifetime milk production, as well as a $39.3 \%$ and $35.7 \%$ increase in lifetime fat and pro- 
tein production, respectively, between cows that were ranked as genetically the best versus genetically the worst on the Dairy Wellness Profit Index (i.e., a US dairy index); moreover, favorable differences in the number of live calves, duration in the lactating herd, cow mortality, and the health events of metritis, mastitis, and lameness were documented (Fessenden et al., 2020). Another US study by McNeel et al. (2017) further confirms results from the present study that cows genetically divergent for fitness traits also manifest as phenotypic differences. McNeel et al. (2017) reported a lower incidence of both lameness and mastitis among 2,875 US Holstein cows that were genetically divergent for wellness traits; there was a 7.4 percentage unit (i.e., $8.54 \%$ vs. $15.94 \%$ ) and a 3.9 percentage unit (i.e., $7.55 \%$ vs. $11.43 \%$ ) difference in the incidence of mastitis and lameness, respectively, for cows ranked as genetically elite compared with cows ranked as genetically inferior (McNeel et al., 2017). In an Irish study, O'Sullivan et al. (2019) reported reduced milk yield but greater milk solids per cow for 177 cows ranked as "elite" on the EBI relative to 95 cows ranked as "national average" on the EBI. Observations of lower milk yield per lactation in the present study and in other Irish studies (Ramsbottom et al., 2012; O'Sullivan et al., 2019) are not unexpected given that the EBI places a negative economic value on milk yield since Irish producers are financially rewarded for producing high quantities of milk constituents as opposed to milk volume itself.

Differences in genetic merit for Irish (Ramsbottom et al., 2012; Connolly et al., 2016) and international (Newton et al., 2017; Fessenden et al., 2020) breeding goals also materialize as favorable monetary differences. Indeed an analysis of 1,131 commercial Irish dairy herds confirmed such; Ramsbottom et al. (2012) concluded that higher EBI herds had superior financial performance, where each unit increase in herd EBI was associated with a $€ 1.94$ ( $\mathrm{SE}=0.42$ ) increase in net margin per cow; the result was not different from the expectation of $€ 2$. Moreover, a study on 2,185 US cows from 5 herds documented that each unit increase in the Dairy Wellness Profit value was associated with a $\$ 1.84$ $(P<0.0001)$ higher lifetime profit (Fessenden et al., $2020)$; the expectation was $\$ 2$. Although the study by Newton et al. (2017) was based on just 3 herds, higher genetic merit for the Australian total merit index (i.e., Balanced Performance Index) was also associated with favorable economic returns. While the present study did not have access to financial performance data to quantify the association between genetic merit and monetary returns, the financial performance reported by Ramsbottom et al. (2012) were extrapolated to the present study; the average dairy producer who maintains a herd of very high EBI cows relative to very low EBI cows (mean EBI of $€ 176$ versus $€ 106$ in the present study) should generate an additional €136 net margin per cow-lactation, or €10,592 per herd-year (of 78 cows), which is line with expectations.

\section{Overestimated Fertility Performance}

Cows excelling in either EBI, fertility subindex, or EBV for calving interval or survival outperformed their genetically inferior contemporaries for reproductive performance; such findings are supported by Cummins et al. (2012) and O'Sullivan et al. (2020), which were based on Irish controlled experimental results. That said, the overestimation of the expected effect of calving interval EBV on phenotypic performance in the present study warranted further investigation. Overestimation in the effect of the EBV itself is not an issue for selection per se when the EBV is considered in single-trait selection, since the animal with the best EBV is still the best phenotypic performer. However, such a conclusion may not be true when a deviation in phenotypic performance relative to a difference in EBV exists if that EBV is included in the breeding goal with sizable relative emphasis; calving interval has a relative emphasis of $22 \%$ in the EBI (Supplemental Table S1). As the EBI is a linear function of each of its component traits, it is possible for an animal to rank high on overall EBI if it excels in genetic merit for calving interval but is poor in genetic merit for other traits (Berry and Ring, 2020); such a scenario could result in the incorrect identification of the best animal when selection is based at the level of the overall EBI (i.e., re-ranking effect at the level of the EBI).

The present study is not the first to report a weak regression coefficient between calving interval EBV and its associated phenotype. Based on a data set of 38,619 Irish commercial beef cows, McHugh et al. (2014) documented a regression coefficient of just 0.58 $(\mathrm{SE}=0.16)$ when regressing calving interval on $\mathrm{EBV}$ for calving interval; Dunne et al. (2019) documented a similar coefficient of $0.57(\mathrm{SE}=0.06)$ when regressing phenotypic calving interval of Irish dairy cows on their respective EBV for calving interval. None of the Irish data analyzed by Dunne et al. (2019) were used in the present study. Dunne et al. (2019), however, also stratified 1,059 Irish dairy herds (125,035 cows) according to their best linear unbiased estimates (BLUE) for calving interval and then fitted an interaction between EBV and the herd-level BLUE strata. Cows that resided in the worst BLUE herds improved their phenotypic calving interval by $1.50 \mathrm{~d}(\mathrm{SE}=0.06)$ per 1-unit change in EBV for calving interval; cows that resided in the best BLUE herds improved their phenotypic calving interval by just $0.35 \mathrm{~d}$ ( $\mathrm{SE}=0.07$; Dunne et al., 2019) per unit 
change in calving interval EBV. A similar genotype-byenvironment interaction was described in an analysis of dairy cow fertility data from New Zealand (Craig et al., 2018). Moreover, Visscher et al. (2008) reported findings of differing genetic and environmental variance for animals managed in good husbandry environments relative to poor husbandry environments. The present study noted that descendants from cows with the best genetic merit for calving interval would benefit least from further genetic selection, while the opposite was true for descendants from cows with the worst genetic merit. To add to this, the interval between the cow calving and the mating start date of the herd had a considerable impact on the estimated regression coefficient of phenotypic calving interval on EBV for calving interval; cows that had a longer interval between calving and the mating start date (i.e., a long voluntary waiting period) had the lowest regression coefficient. Findings from the present study, together with that of the genotype-by-environment interaction effects reported elsewhere (Visscher et al., 2008; Craig et al., 2018; Dunne et al., 2019) could be suggestive of heterogeneous management within herd for cows that are divergent for fertility EBV; further investigation of the effect of heterogeneous management on the (co) variance components for calving interval are necessary. One plausible hypothesis is that the most genetically elite cows for fertility simply do not have the opportunity to express their full genetic potential within the constraints of seasonal production systems. An industry target for Irish dairy cows is one that maintains a calving interval of $365 \mathrm{~d}$; such a constraint is especially difficult to achieve for cows calved a long time before the herd planned mating start date. By way of example (and illustrated in Figure 2), a cow that calves $2 \mathrm{~d}$ after the herd planned start of calving date (i.e., January 22 ) will usually resume normal ovarian activity and ovulation within 45 d (i.e., March 7; Forde et al., 2011) and show regular estrus cycles thereafter at 18- to 24-d intervals (Forde et al., 2011). Since breeding on the March 7 (i.e., calving $+45 \mathrm{~d}$ ) would result in a subsequent calving before the herd planned start of calving date, the cow must be withheld from breeding until at least the April 20 (i.e., planned mating start date). Under such a scenario, assuming a 21-d estrus cycle, it is likely the aforementioned cow is unlikely to conceive again before May 9 in the subsequent year, suggesting the cow could not possibly achieve a calving interval of $365 \mathrm{~d}$ within the bounds of the seasonal production system (Figure 2). On the other hand, a cow that calves on the March 10 is unlikely to be withheld from breeding as she will only return to normal estrus cycles after the herd has started mating; this cow could achieve a calving interval of $365 \mathrm{~d}$ (Figure 2). Visscher et al.
(2008) advised that variance components and response to selection would be best estimated when the model is adjusted for known environmental factors (e.g., the herd withholding period); (co)variance components for calving interval in Ireland have not been updated since 2010, a time when the herd withholding period would have been a lesser issue due to more lax management systems. In any case, what the present study clearly demonstrates, is that a considerable beneficial phenotypic response will arise in the progeny of genetically inferior dams when they are mated to genetically elite service sires for calving interval. That said, further investigation into the current model, trait definition, and (co)variance components for calving interval is warranted.

\section{Traits of Lesser Economic Importance}

Results from the present study substantiate that the national dairy breeding goal is successful in deciphering phenotypic responses among animals divergent on either the EBV itself or as part of the balanced breeding goal. Moreover, the breeding goal prioritizes traits of higher economic importance (Supplemental Table S1); that said, animals differing on EBI also deviate phenotypically for the traits that have a lesser economic importance in the breeding goal. For example, as EBI improves (i.e., increases) the incidence of lameness decreases, as does SCC, even though lameness and SCC represent just $2.2 \%$ and $0.9 \%$ of the overall breeding goal, respectively; moreover, lameness and SCC have an antagonistic genetic correlation with other traits in the breeding goal (e.g., higher milk production).

It is well documented that dairy cattle have inferior carcass attributes relative to their beef counterparts (Twomey et al., 2020b). That said, the present study observed a favorable (yet numerically small) association between increasing EBI and heavier progeny carcasses; that is encouraging, given that specialized beef production is not the primary focus of dairy producers; hence, the carcass merit of service dairy sires is likely of minor concern to dairy producers. Of unease though, is that as EBI increases, progeny carcass conformation and fat deteriorate. Meat processors in Ireland impose financial penalties on animals that do not meet strict carcass conformation grades, and dairy-origin carcasses are often prone to receiving such penalties (Kenny et al., 2020). Nonetheless, such a result regarding declining progeny carcass conformation and fat attributes is not surprising given that the combined relative emphasis of those traits in the EBI in 2020 was just $2.8 \%$, and it is antagonistically correlated with other traits that have a higher economic importance in the breeding goal (e.g., milk and fertility). Going forward, it may be necessary 


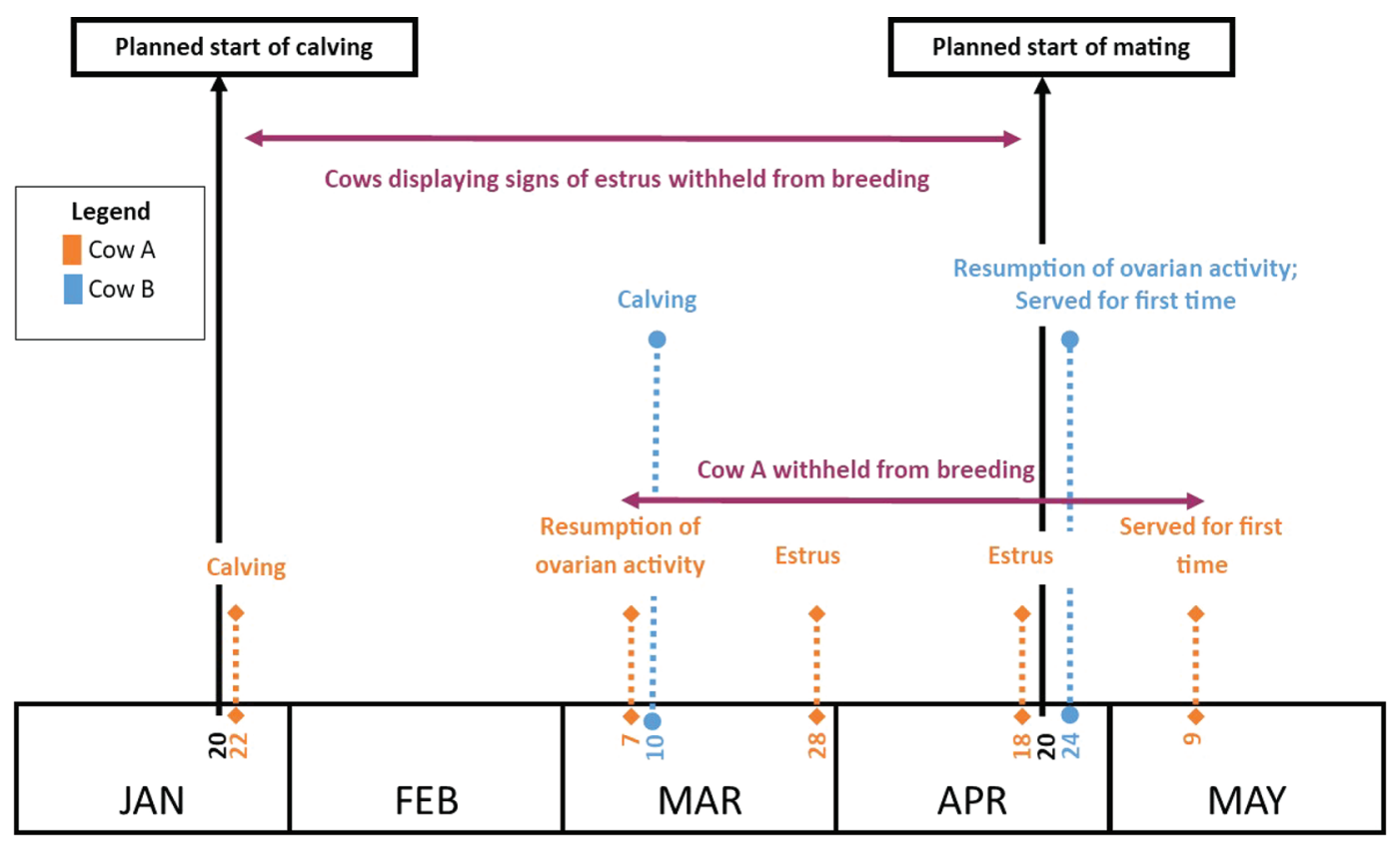

Figure 2. Diagrammatic illustration of the potential heterogeneous management in seasonal calving systems for cows that have calved a long (cow A) or a short period (cow B) before the herd's planned start of mating. The shortest possible calving interval for cow A is $386 \mathrm{~d}$ (i.e., interval from January 20 to February 9) and 320 d (i.e., interval from March 10 to January 24) for cow B; the perceived worse calving interval of cow $\mathrm{A}$ is a function of the producer withholding the cow from breeding due to the constraints of the seasonal calving system, not inferior fertility of the cow herself.

to re-evaluate the implications of further deterioration in the beef merit of dairy carcasses, and hence the emphasis in the total merit index.

\section{CONCLUSIONS}

Validation results from the present study conclude that genetically elite EBI cows produce a greater yield and concentration of both milk fat and milk protein, despite a lower milk volume; these cows also have superior reproductive performance, incur fewer udder and lameness events, and have a lighter mature liveweight. For the progeny of genetically elite EBI animals, they are less prone to dystocia at birth and their carcasses are heavier and fatter at slaughter, albeit of a poorer conformation. Results from the present study will be useful to the agricultural industry in its entirety to provide confidence that the traits included in the EBI indeed improve phenotypic performance, although room for improvement exists. Extension of the methods used in the present study to other populations demonstrates the usefulness of total merit indexes in achieving sustainable and cumulative phenotypic gains in performance, even among antagonistically correlated traits, or traits with low heritability. Moreover, the methods applied in the present study can be replicated internationally to demonstrate that genetic divergence translates to phenotypic divergence, and by extension, the value of genetics to improving farm profitability.

\section{ACKNOWLEDGMENTS}

This publication has emanated from research supported by a research grant from Science Foundation Ireland and the Department of Agriculture, Food and the Marine (Dublin, Ireland) on behalf of the government of Ireland under the grant 16/RC/3835 (VistaMilk). The authors have not stated any conflicts of interest.

\section{REFERENCES}

Berry, D. P. 2018. Symposium review: Breeding a better cow-Will she be adaptable? J. Dairy Sci. 101:3665-3685. https://doi.org/10 .3168/jds.2017-13309.

Berry, D. P., P. R. Amer, R. D. Evans, T. Byrne, A. R. Cromie, and F. Hely. 2019. A breeding index to rank beef bulls for use on dairy females to maximize profit. J. Dairy Sci. 102:10056-10072. https:/ /doi.org/10.3168/jds.2019-16912.

Berry, D. P., J. Coyne, B. Coughlan, M. Burke, J. McCarthy, B. Enright, A. R. Cromie, and S. McParland. 2013a. Genetics of milking characteristics in dairy cows. Animal 7:1750-1758. https://doi .org/10.1017/S1751731113001511.

Berry, D. P., J. F. Kearney, K. Twomey, and R. D. Evans. 2013b. Genetics of reproductive performance in seasonal calving dairy cattle production systems. Ir. J. Agric. Food Res. 52:1-16.

Berry, D. P., and S. C. Ring. 2020. Observed progeny performance validates the benefit of mating genetically elite beef sires to dairy females. J. Dairy Sci. 103:2523-2533. https://doi.org/10.3168/jds .2019-17431. 
Berry, D. P., L. Shalloo, A. R. Cromie, R. F. Veerkamp, P. Dillion, P. R. Amer, J. F. Kearney, R. D. Evans, and B. Wickham. 2007. The economic breeding index: A generation on. Irish Cattle Breeding Federation. Accessed Nov. 18, 2020. https://www.icbf.com/wp/wp -content/uploads/2013/06/economic_breeding_index.pdf.

Cole, J. B., and P. M. VanRaden. 2018. Symposium review: Possibilities in an age of genomics: The future of selection indices. J. Dairy Sci. 101:3686-3701. https://doi.org/10.3168/jds.2017-13335.

Connolly, S. M., A. R. Cromie, and D. P. Berry. 2016. Genetic differences based on a beef terminal index are reflected in future phenotypic performance differences in commercial beef cattle. Animal 10:736-745. https://doi.org/10.1017/S1751731115002827.

Craig, H. J. B., K. Stachowicz, M. Black, M. Parry, C. R. Burke, S. Meier, and P. R. Amer. 2018. Genotype by environment interactions in fertility traits in New Zealand dairy cows. J. Dairy Sci. 101:10991-11003. https://doi.org/10.3168/jds.2017-14195.

Crump, R. E., N. R. Wray, R. Thompson, and G. R. Simm. 1997. Assigning pedigree beef performance records to contemporary groups taking account of within herd calving patterns. Anim. Sci. 65:193198. https://doi.org/10.1017/S1357729800016490.

Cummins, S. B., P. Lonergan, A. C. O. Evans, D. P. Berry, R. D. Evans, and S. T. Butler. 2012. Genetic merit for fertility traits in Holstein cows: I. Production characteristics and reproductive efficiency in a pasture-based system. J. Dairy Sci. 95:1310-1322. https://doi.org/10.3168/jds.2011-4742.

Dunne, F. L., S. McParland, M. M. Kelleher, S. W. Walsh, and D. P. Berry. 2019. How herd best linear unbiased estimates affect the progress achievable from gains in additive and nonadditive genetic merit. J. Dairy Sci. 102:5295-5304. https://doi.org/10.3168/jds .2018-16119.

Englishby, T. M., G. Banos, K. L. Moore, M. P. Coffey, R. D. Evans, and D. P. Berry. 2016. Genetic analysis of carcass traits in beef cattle using random regression models. J. Anim. Sci. 94:1354-1364. https://doi.org/10.2527/jas.2015-0246.

Evans, R. D., P. Dillon, F. Buckley, D. P. Berry, M. Wallace, V. Ducrocq, and D. J. Garrick. 2006. Trends in milk production, calving rate and survival of cows in 14 Irish dairy herds as a result of the introgression of Holstein-Friesian genes. Anim. Sci. 82:423-433. https://doi.org/10.1079/ASC200660.

Fessenden, B., D. J. Weigel, J. Osterstock, D. T. Galligan, and F. Di Croce. 2020. Validation of genomic predictions for a lifetime merit selection index for the US dairy industry. J. Dairy Sci. 103:1041410428. https://doi.org/10.3168/jds.2020-18502.

Forde, N., M. E. Beltman, P. Lonergan, M. Diskin, J. F. Roche, and M. A. Crowe. 2011. Oestrous cycles in Bos taurus cattle. Anim. Reprod. Sci. 124:163-169. https://doi.org/10.1016/j.anireprosci 2010.08.025.

García-Ruiz, A., J. B. Cole, P. M. VanRaden, G. R. Wiggans, F. J. Ruiz-López, and C. P. Van Tassell. 2016. Changes in genetic selection differentials and generation intervals in US Holstein dairy cattle as a result of genomic selection. Proc. Natl. Acad. Sci. USA 113:E3995-E4004. https://doi.org/10.1073/pnas.1519061113.

Horan, B., J. F. Mee, P. O'Connor, M. Rath, and P. Dillon. 2005. The effect of strain of Holstein-Friesian cow and feeding system on postpartum ovarian function, animal production and conception rate to first service. Theriogenology 63:950-971. https://doi.org/ 10.1016/j.theriogenology.2004.05.014.

Judge, M. M., T. Pabiou, J. Murphy, S. B. Conroy, P. J. Hegarty, and D. P. Berry. 2019. Potential exists to change, through breeding, the yield of individual primal carcass cuts in cattle without increasing overall carcass weight. J. Anim. Sci. 97:2769-2779. https: //doi.org/10.1093/jas/skz152.

Kenny, D., C. P. Murphy, R. D. Sleator, M. M. Judge, R. D. Evans, and D. P. Berry. 2020. Animal-level factors associated with the achievement of desirable specifications in Irish beef carcasses graded using the EUROP classification system. J. Anim. Sci. 98:skaa191. https://doi.org/10.1093/jas/skaa191.

Madsen, P., and J. Jensen. 2008. A User's Guide to DMU. A Package for Analysing Multivariate Mixed Models. Version 6. Release 4.7. Danish Institute of Agricultural Sciences.
McHugh, N., A. R. Cromie, R. D. Evans, and D. P. Berry. 2014. Validation of national genetic evaluations for maternal beef cattle traits using Irish field data. J. Anim. Sci. 92:1423-1432. https:// doi.org/10.2527/jas.2013-6658.

McCarthy, J., and R. F. Veerkamp. 2012. Estimation of genetic parameters for test-day records of dairy traits in a seasonal calving system. J. Dairy Sci. 95:5365-5377. https://doi.org/10.3168/jds .2011-4706.

McNeel, A. K., B. C. Reiter, D. Weigel, J. Osterstock, and F. A. Di Croce. 2017. Validation of genomic predictions for wellness traits in US Holstein cows. J. Dairy Sci. 100:9115-9124. https://doi.org/ $10.3168 /$ jds.2016-12323.

Morton, J. M., R. R. Woolaston, P. Brightling, S. Little, K. L. Macmillan, J. E. Pryce, and G. J. Nieuwhof. 2015. Are high Australian profit ranking sires best in all herds? Findings from the feeding the genes project. Proc. Assoc. Advmt. Anim. Breed. Genet. 21:185-188.

Newton, J. E., M. E. Goddard, H. N. Phuong, M. A. Axford, C. K. M. Ho, N. C. Nelson, C. F. Waterman, B. J. Hayes, and J. E. Pryce. 2017. High genetic merit dairy cows contribute more to farm profit: Case studies of 3 Australian dairy herds. Proc. Assoc. Advmt. Anim. Breed. Genet. 22:19-22.

O'Sullivan, M., S. T. Butler, K. M. Pierce, M. A. Crowe, K. O'Sullivan, R. Fitzgerald, and F. Buckley. 2020. Reproductive efficiency and survival of Holstein-Friesian cows of divergent Economic Breeding Index, evaluated under seasonal calving pasture-based management. J. Dairy Sci. 103:1685-1700. https://doi.org/10.3168/jds .2019-17374.

O'Sullivan, M., B. Horan, K. M. Pierce, S. McParland, K. O'Sullivan, and F. Buckley. 2019. Milk production of Holstein-Friesian cows of divergent Economic Breeding Index evaluated under seasonal pasture-based management. J. Dairy Sci. 102:2560-2577. https:// doi.org/10.3168/jds.2018-15559.

Olori, V. E., T. H. E. Meuwissen, and R. F. Veerkamp. 2002. Calving interval and survival breeding values as measure of cow fertility in a pasture-based production system with seasonal calving. J. Dairy Sci. 85:689-696. https://doi.org/10.3168/jds.S0022-0302(02)74125 -8 .

Pabiou, T., W. F. Fikse, P. R. Amer, A. R. Cromie, A. Nasholm, and D. P. Berry. 2011. Genetic variation in wholesale carcass cuts predicted from digital images in cattle. Animal 5:1720-1727. https:// doi.org/10.1017/S1751731111000917.

Pabiou, T., W. F. Fikse, A. Näsholm, A. R. Cromie, M. J. Drennan, M. G. Keane, and D. P. Berry. 2009. Genetic parameters for carcass cut weight in Irish beef cattle. J. Anim. Sci. 87:3865-3876. https://doi.org/10.2527/jas.2008-1510.

Pryce, J. E., T. T. T. Nguyen, M. Axford, G. Nieuwhof, and M. Shaffer. 2018. Symposium review: Building a better cow-The Australian experience and future perspectives. J. Dairy Sci. 101:37023713. https://doi.org/10.3168/jds.2017-13377.

Ramsbottom, G., A. R. Cromie, B. Horan, and D. P. Berry. 2012. Relationship between dairy cow genetic merit and profit on commercial spring calving dairy farms. Animal 6:1031-1039. https:// doi.org/10.1017/S1751731111002503.

Ring, S. C., D. A. Graham, R. G. Sayers, N. Byrne, M. M. Kelleher, M. L. Doherty, and D. P. Berry. 2018b. Genetic variability in the humoral immune response to bovine herpesvirus-1 infection in dairy cattle and genetic correlations with performance traits. J. Dairy Sci. 101:6190-6204. https://doi.org/10.3168/jds.2018-14481.

Ring, S. C., D. C. Purfield, M. Good, P. Breslin, E. Ryan, A. Blom, R. D. Evans, M. L. Doherty, D. G. Bradley, and D. P. Berry. 2019. Variance components for bovine tuberculosis infection and multi-breed genome-wide association analysis using imputed whole genome sequence data. PLoS One 14:e0212067. https://doi.org/10 .1371/journal.pone.0212067.

Ring, S. C., A. J. Twomey, N. Byrne, M. M. Kelleher, T. Pabiou, M. L. Doherty, and D. P. Berry. 2018a. Genetic selection for hoof health traits and cow mobility scores can accelerate the rate of genetic gain in producer-scored lameness in dairy cows. J. Dairy Sci. 101:10034-10047. https://doi.org/10.3168/jds.2018-15009. 
Roche, J. R., D. P. Berry, A. M. Bryant, C. R. Burke, S. T. Butler, P. G. Dillon, D. J. Donaghy, B. Horan, K. A. Macdonald, and K. L. Macmillan. 2017. A 100-Year Review: A century of change in temperate grazing dairy systems. J. Dairy Sci. 100:10189-10233. https://doi.org/10.3168/jds.2017-13182.

Schmitz, F., R. W. Everett, and R. L. Quaas. 1991. Herd-year-season clustering. J. Dairy Sci. 74:629-636. https://doi.org/10.3168/jds .S0022-0302(91)78210-6.

Stachowicz, K., G. M. Jenkins, P. R. Amer, D. P. Berry, M. M. Kelleher, F. J. Kearney, R. D. Evans, and A. R. Cromie. 2018. Changes to the genetic evaluation of fertility in Irish dairy cattle. Page 53 in Proc. 2018 Interbull Meeting. https://journal.interbull.org/index .php/ib/article/view/1449.

Twomey, A. J., R. G. Sayers, R. I. Carroll, N. Byrne, O. Brien, M. L. Doherty, J. C. McClure, D. A. Graham, and D. P. Berry. 2016. Genetic parameters for both a liver damage phenotype caused by Fasciola hepatica and antibody response to Fasciola hepatica phenotype in dairy and beef cattle. J. Anim. Sci. 94:4109-4119. https: //doi.org/10.2527/jas.2016-0621.

Twomey, A. J., A. R. Cromie, N. McHugh, and D. P. Berry. 2020a. Validation of a beef cattle maternal breeding objective based on a cross-sectional analysis of a large national cattle database. J. Anim. Sci. 98:skaa322. https://doi.org/10.1093/jas/skaa322.
Twomey, A. J., S. C. Ring, N. McHugh, and D. P. Berry. 2020b. Carcass and efficiency metrics of beef cattle differ by whether the calf was born in a dairy or a beef herd. J. Anim. Sci. 98:skaa321. https: //doi.org/10.1093/jas/skaa321.

Veerkamp, R. F., P. Dillon, E. Kelly, A. R. Cromie, and A. F. Groen. 2002. Dairy cattle breeding objectives combining yield, survival and calving interval for pasture-based systems in Ireland under different milk quota scenarios. Livest. Prod. Sci. 76:137-151. https: //doi.org/10.1016/S0301-6226(02)00006-4.

Visscher, P. M., W. G. Hill, and N. R. Wray. 2008. Heritability in the genomics era-Concepts and misconceptions. Nat. Rev. Genet. 9:255-266. https://doi.org/10.1038/nrg2322.

Wiggans, G. R., J. B. Cole, S. M. Hubbard, and T. S. Sonstegard. 2017. Genomic selection in dairy cattle: The USDA experience. Annu. Rev. Anim. Biosci. 5:309-327. https://doi.org/10.1146/ annurev-animal-021815-111422.

\section{ORCIDS}

S. C. Ring ๑ https://orcid.org/0000-0001-7495-4286

R. D. Evans $\odot$ https://orcid.org/0000-0003-0370-5949

D. P. Berry (ํ) https://orcid.org/0000-0003-4349-1447 